\title{
Redes de proteção e a decantação dos direitos das crianças
}

\author{
Marcelo Baumann Burgos*
}

https://orcid.org/0000-0001-9766-8848

Apesar de claramente inspirado no modelo de Welfare State, típico do que tem sido chamado de "constitucionalismo democrático" (que caracteriza a filosofia das constituições adotadas por parte dos países europeus no contexto do pós-Segunda Guerra), o sistema de direitos criado no Brasil em 1988 foi moldado segundo uma lógica distinta daquela cara a esse tipo de estado. Com maior ou menor clareza desse movimento, a partir de 1988, Legislativo e Executivo aprovam leis que pretendem criar programas de ação segundo um modelo distinto do estado burocrático característico do ws.

Assim é que leis como o Estatuto da Criança e do Adolescente - ECA (1990), o Estatuto da Cidade (2001) e o Estatuto do Idoso (2003), além do modelo adotado pelo Sistema Único de Assistência Social - Suas ${ }^{1}$, implantado em 2004, pressupõem um tipo de articulação em rede entre estado e sociedade, com previsão de ampla participação do Ministério Público, e incentivo à intensa mobilização do Judiciário para administração de conflitos envolvendo interesses e bens de cidadania. Isso fez com que a articulação em rede ganhasse relevância para uma sociologia do direito preocupada com a chamada judicialização da política pública (Werneck Vianna e Burgos, 2005; Casagrande, 2008), e com a justiça de proximidade, desenvolvida sobretudo na Europa, nos anos de 1990 (Bonnan, 2001).

\footnotetext{
* Pontifícia Universidade Católica do Rio de Janeiro, Rio de Janeiro, Brasil.

1. Para uma contextualização da implantação do Suas, ver Pereira (2007).
} 
No campo da ciência da administração pública, a gestão em rede tem sido tratada basicamente como um problema de coordenação, o que pressupõe, como lembra Sonia Fleury (2005), que as redes "podem ser compatíveis com distintas orientações políticas em relação aos direitos sociais e ao papel do Estado, do mercado e da sociedade na garantia de direitos e na provisão de serviços”. No entanto, como também nota Fleury, políticas organizadas em rede apresentam severas limitações "no cumprimento de certas funções públicas, de caráter nitidamente estatal, como, por exemplo, a garantia de direitos sociais e a regulação" (Idem, p. 87).

Mais recentemente, como sustentam Mota e Bittencourt (2019), a literatura da ciência política e da administração sobre a gestão em rede vem ganhando maior densidade. Segundo eles, estaria em curso uma nova geração de estudos sobre o tema, com mais foco na diversidade de desenhos das redes, e nos fatores críticos para seu sucesso, entre os quais podemos destacar a excessiva fragmentação decisória e problemas de accountability, decorrentes da diminuição da capacidade de controle das ações dos diversos atores intervenientes, tanto por parte do poder público, quanto por parte dos cidadãos.

Apesar de seu grande alcance sobre a vida social, de modo especial para os segmentos mais vulneráveis da sociedade, a gestão em rede permanece pouco valorizada como problema de pesquisa sociológica. Talvez a melhor aproximação sociológica com o tema venha do estudo de Boltanski e Chiapello (2009), que assumem o modelo em rede como característica importante do espírito de uma época. O tipo ideal que eles denominam como "cidade por projetos", o qual, cronologicamente, se seguiria ao da "cidade industrial" (bem como ao da "cidade mercantil"), sintetiza bem aspectos de um mundo transformado pelas reformas implementadas nos países do centro do capitalismo entre os anos de 1970 e 1980. As bases de legitimidade da "cidade por projetos", afirmam os autores, se apoiariam na lógica dos projetos e das redes, conformando um mundo "conexionista", que se distinguiria do mundo industrial e mercantil em vários aspectos: por substituir a lógica abstrata de tempo por uma temporalidade concreta associada à duração das conexões e a lógica de espaço vertical e horizontal pela de rede; por não ser regulado pela projeção de uma equivalência geral que, no mundo mercantil, servia à formação de preços; e por emprestar maior importância às relações pessoais - "em tal configuração, sublinham os autores, já não se pode tratar o trabalho como mercadoria destacável da pessoa daquele que o exerce” (Idem, p. 165).

$\mathrm{Na}$ configuração da "cidade por projetoo", o ator típico seria aquele que se move por meio de conexões em redes. "A flexibilidade e a capacidade de adaptar-se e aprender incessantemente tornam-se seus principais trunfos, mais importantes que as especialidades técnicas (os saberes mudam tão depressa!) e sua experiência." Seus métodos de trabalho, arrematam os autores, "são elaborados em função de necessi- 
dades sempre mutáveis; as pessoas se auto-organizam, inventam regras tópicas, que não podem ser abarcadas e racionalizadas globalmente" (Idem, p. 170). Seria parte da dinâmica desse mundo em rede, portanto, a atomização dos processos de trabalho, condicionados em cada caso pelo tipo de arranjo existente entre a dimensão sistêmica e a dimensão subjetiva - que, nesse mundo conexionista descrito por Boltanski e Chiapello, "estariam muito imbricadas".

As considerações de Boltanski e Chiapello quanto às novas formas de relação entre a dimensão sistêmica e a subjetiva colocadas em movimento pela lógica das redes podem servir de base para uma abordagem sociológica de políticas sociais organizadas em rede, permitindo maior atenção à forma como os atores constroem na experiência da rede o significado de suas ações. Neste artigo, pretendemos discutir a articulação em rede com base em uma pesquisa voltada para a apreciação de como diferentes atores compartilham a responsabilidade pela proteção de crianças e adolescentes, em especial no que se refere ao direito à escolarização.

O estudo sociológico do processo de decantação constitucional dos direitos da criança e adolescente, bem como das novas agências criadas pelo ECA para a sua operacionalização, ainda não foi plenamente realizado ${ }^{2}$. Em especial quando se considera, como aponta Fulvia Rosemberg (2008), o processo de apropriação cultural dessas novas formas jurídicas em uma dimensão tão sensível para qualquer sociedade, como é a do processo de formação das novas gerações. Para os fins deste trabalho, assumimos que, ao menos no que tange aos direitos das crianças e adolescentes, a análise da decantação constitucional não pode prescindir de um estudo mais aprofundado das assim chamadas "redes de proteção dos direitos da criança e adolescente" 3 .

Como propõe Renato Lessa (2008), a questão da decantação constitucional remete ao "espectro de intérpretes autorizados", e quanto maior ele for, "tanto mais largas as possibilidades de interpretação, atribuição e expectativas e, ao fim e ao cabo, de constitucionalização da vida" (Idem, p. 386). Para efeitos deste estudo, partimos da premissa de que as redes de proteção são constituídas por atores que realizam in acto a interpretação dos direitos da criança, ao mesmo tempo que constroem o próprio significado da ideia de rede. Por isso, a hipótese que orientou o recorte do material empírico foi a de que a percepção dos profissionais das diferentes agências sobre o direito da criança tem importante repercussão na forma pela qual essas agências atuam em rede; em contrapartida, o modo como percebem sua atuação na rede impacta o modo pelo qual praticam o direito da criança.

2. Para um balanço dos 25 anos do ECA, ver Unicef (2015).

3. O termo "rede de proteção" não está formalmente colocado na legislação, mas se impôs como uma categoria recorrente entre os profissionais das diferentes agências. Sobre esse ponto, vale a pena ver o trabalho de Oliveira (2015). Ver também Castro (2018). 
A pesquisa empírica envolveu os atores: escola, conselho tutelar (CT), promotorias de direito da criança e adolescente do Ministério Público, e centros de referência de assistência social (CRAS). A seguir, apresentaremos seus principais resultados; ao final, chamaremos a atenção para o fato de que, embora a experiência de políticas em rede venha gerando uma espécie nova de cultura profissional, as evidências apontam que ainda estamos longe de transitar para um novo modelo de gestão, e que isso talvez nunca venha a ocorrer, o que certamente nos impõe a necessidade de refletir com maior profundidade a respeito dos impactos desse processo inconcluso sobre a garantia do bem público que se pretende sustentar, que é o da proteção das crianças e adolescentes.

\section{A pesquisa}

A favela da Rocinha nos serviu de território de referência ${ }^{4}$, e a partir dela realizamos um mapeamento preliminar das agências que, direta ou indiretamente, ali participam da rede de proteção. Além das escolas, inserimos no desenho da pesquisa o Conselho Tutelar da região, o Centro de Referência de Assistência Social (Cras), o Centro de Referência Especializado de Assistência social (Creas), o Ministério Público e as Unidades Básicas de Saúde. Em decorrência de dificuldades operacionais, tivemos de deixar de fora o Creas e as Unidades Básicas de Saúde, mesmo sabendo de sua grande importância para as redes de proteção 5 .

A pesquisa foi desenvolvida a partir de uma abordagem qualitativa, baseada em entrevistas, realizadas entre abril e junho de 2017, com os profissionais que atuam nessas diferentes agências ${ }^{6}$. Em uma visão geral do material empírico, podemos apontar duas tendências até certo ponto contraditórias. De um lado, a sugestão de que a experiência com o direito da criança e com a sua estruturação em rede produziu uma

4. Favela situada na Zona Sul do Rio de Janeiro, e que, com seus mais de 70 mil habitantes, foi considerada pelo Censo do IBGE de 2010 a maior favela brasileira em população.

5. O empreendimento foi realizado por uma equipe composta por catorze estudantes de graduação de Ciências Sociais, duas mestrandas e uma doutoranda também em Ciências Sociais, a quem aproveito para agradecer. São eles: Ana Laura Cannizza, Bruna Camilo, Bruno Delecave, Caroline Bernardoni, Dorlene Meireles, Guido Dowsley, Isabella Almeida, João Pedro Menezes, Lucas Machado, Mariana Casmamie, Pattrick Ely Pinheiro, Rafaelle Monteiro de Castro, Renata Thomaz, Sarah Laurindo, Vera Teresa Balieiro A. da Costa, Vinicius M. Melo e Yago Reis.

6. Foram realizadas 33 entrevistas, com cinco conselheiros tutelares e quatro técnicos do mesmo CT; oito professores, além da diretora e diretora adjunta, de uma escola de ensino fundamental com cerca de oitocentos alunos, quase todos moradores da Rocinha; três promotores, da promotoria de Tutela Coletiva de Proteção à Educação, da promotoria de Tutela Coletiva da Infância e da Juventude, e da Promotoria de Tutela individual da Infância e da Juventude; e seis profissionais do Cras, entre os quais uma coordenadora, duas assistentes sociais, uma pedagoga, um psicólogo e um orientador social. As entrevistas foram transcritas e analisadas por meio do software Atlas TI. 
gramática compartilhada entre os profissionais das diferentes agências, o que aparece de forma mais evidente quando exploramos o material que trata da percepção da rede. E de outro, a indicação de que subsistem claras diferenças e dissonâncias quanto à forma com que os profissionais de cada agência percebem o direito da criança e a sua atuação na rede. Assim, se a primeira tendência indica compartilhamento de uma gramática comum, ao menos no que se refere à imaginação política, jurídica e institucional criada pelo ECA, a segunda tendência realça o quanto a noção de rede ainda esbarra em barreiras comunicativas, que tanto vêm da lógica compartimentada em que está estruturada a gestão do social, quanto das diferentes culturas profissionais que a lógica da rede precisa interligar.

\section{A gramática comum da rede}

Quanto à percepção da rede, identificamos que duas vertentes atravessam a fala dos entrevistados, indicando o compartilhamento de uma gramática comum. $\mathrm{Na}$ primeira, entrevistados das diferentes agências tendem a convergir em torno da contraposição entre o que seria o modelo ideal da rede e uma realidade que estaria aquém do que seria desejado. Neste caso, prevalece uma concepção sistêmica, que tende a situar os profissionais e suas agências como parte de uma engrenagem mais ampla sobre a qual nem mesmo os promotores parecem ter pleno controle. No trecho a seguir, um dos promotores entrevistados, respondendo a uma pergunta sobre o encaminhamento adotado em caso de internação, fala, em tom de desabafo, que “o sistema 'tá todo errado". Com isso, não deixa de revelar como a antinomia entre a realidade concreta das instituições e o ideal de funcionamento da rede serve de referencial estruturante da forma como ele lê a falta de efetividade da rede:

\section{Promotor:}

$O$ adolescente que pratica ato infracional recebe tudo ou nada: o nada são essas medidas em meio aberto que nem sempre são executadas, e o menino vai lá pra assinar um papel e ponto, isso éum nada; o o tudo é a internação, que é esse encarceramento. Então ele não recebe nenhuma medida socioeducativa, na verdade não existe medida socioeducativa; então, assim, você vê que, aonde você procurar, dá errado, o sistema tá todo errado.

Como se vê, ao menos no que se refere à produção de uma imaginação, o ECA parece estar cumprindo um dos papéis que se esperam de uma lei inovadora, servindo de parâmetro para aquilo que os operadores gostariam que acontecesse. $\mathrm{O}$ direito se inscreve na experiência dos operadores, ainda que não na prática, para evocar sugestiva proposição de François Dubet (1994). 
A segunda vertente, extraída da análise do material sobre a percepção da rede, é aquela que aponta para a convergência entre os entrevistados na delimitação de uma espécie de antinomia entre conflito e cooperação. A rede costuma ser percebida por profissionais de diferentes agências como uma fonte permanente de conflitos, seja porque haveria sobreposição de competências, seja porque a outra agência nem sempre age como deveria. Os profissionais do CT, em especial, costumam se ver como vítimas das sobreposições por parte de outras agências; e os da escola, por seu turno, tendem a identificar as agências da rede como potenciais fontes de conflito.

No trecho da entrevista citado a seguir, em resposta a uma pergunta sobre como percebe a relação do CT com agências como o Creas, a escola, a polícia e a família da criança/adolescente, um conselheiro tutelar ressalta que elas tendem a acreditar num senso comum de que o "Conselho Tutelar tem poder para tudo", muito além do que está previsto no Estatuto da Criança e do Adolescente (ECA).

Conselheiro Tutelar:

Eles acham que o CT tem poder pra tudo, manda lá pro conselho pra resolver, que ele resolve; $e$ não é assim, somos limitados, temos nossas demandas e até um certo ponto pra poder agir.

Em outras entrevistas, conselheiros tutelares também acusam a escola de contribuir para criar uma imagem equivocada do CT como um “órgão repressivo", um "bicho papão"7. Para eles, o resultado dessa postura seria a produção de um imaginário que, ao invés de favorecer a ideia de que o CT é um órgão de proteção que, inclusive, poderia auxiliar a escola na defesa da criança/adolescente em situações nas quais ela/ele estaria exposta/o à violência e à negligência externas ao seu controle, gera, ao contrário, um tipo de percepção que compromete a possibilidade de complementaridade entre CT e escola.

Essa imagem negativa do CT que, segundo os conselheiros, predominaria na escola, talvez encontre uma boa explicação quando se considera que os professores têm pouca relação direta com a rede. No trecho a seguir, ao reagir à nossa pergunta sobre a sua percepção a respeito do CT, uma professora enfatiza que a relação com essa agência, e poderíamos dizer, com as demais agências da rede, fica muito concentrada na direção da escola. Essa fala - reiterada por outros professores - aponta para a tendência de se reduzir a participação da rede na vida escolar a uma dimensão exclusivamente institucional, que contribui para fazer com o que o professor não se perceba como um profissional que, ao menos potencialmente, faz parte de um trabalho coletivo de socialização das novas gerações, cujo alcance não se restringe ao espaço escolar.

7. Para um estudo da relação do CT com a comunidade escolar, ver a segunda seção de Burgos (2014). 
Professora:

A direção é que faz contato como Conselho Tutelar, quando éum aluno que não consegue contato com a familia. O Ministério Público, às vezes, vem ver a distribuição de livros e etc., comparece na escola, mas muito pouco assim... Sobre o Conselho Tutelar, eu acho assim: quanto menos presente o Conselho Tutelar 'tá, menos problema eu acho que existe naquela escola, né? E... Eu já ouvi falar bem do Conselho Tutelar, mas também já ouvi falar mal do Conselho Tutelar, então, nem sempre funciona como deveria.

O conflito entre escola e o CT talvez seja o mais evidente e importante, mas os conflitos de competência também emergem na relação entre outras agências. São muito comuns, por exemplo, na relação entre o MP e o CT, situações que, de acordo com essa promotora, seriam favorecidas pelo Disque 100 (serviço de denúncias de violações contra crianças e adolescentes), que encaminha a mesma denúncia para as duas agências:

\section{Promotora:}

Quem interfere... quem deve agir primeiro, de acordo com a lógica do ECA, éo Conselho Tutelar. Eassim, há muitos anos aqui no estado do Rio de Janeiro vinham acontecendo atuações sobrepostas, que foram criadas quando veio o Disque 100. Ai se criou um canal direto... o conselho tutelar recebia as denúncias, e o Ministério Público, paralelamente, recebia as mesmas denúncias.

Quando falam em cooperação, os profissionais das diferentes agências pesquisadas indicam pelo menos três principais aspectos, que concorrem para favorecê-la: a valorização das relações pessoais, a importância da troca de informações e os encontros presenciais por meio de reuniões.

A valorização das relações pessoais no cotidiano das agências aparece de modo recorrente como condição para a efetividade de uma determinada ação. Nesse sentido, a preocupação com a rotatividade dos profissionais em determinadas funções é apontada como um fator que pode produzir rupturas no funcionamento da rede. A preocupação dos conselheiros com a rotatividade de promotores em suas funções ou, inversamente, a preocupação dos promotores com a rotatividade dos conselheiros são exemplos significativos dessa situação.

Ao responder a uma pergunta sobre como é a relação com o Judiciário e com o MP, a conselheira deixa explícita a proximidade que ela estabelece com o juiz, que facilita as demandas de reunião e a resolução de casos específicos. Também é possível perceber a adesão ao uso de tecnologias digitais de informação como o Whats $A p p$, utilizado para estabelecer a comunicação em tempo real, já que é bem mais acessível 
que o uso de relatórios e ofícios. Já em relação ao MP, ela manifesta a sua preocupação por conta do que percebe como uma alta rotatividade de seus membros:

\section{Conselheira Tutelar:}

Com o MP, eles mandam pra gente o fício, a gente manda o relatório e, às vezes, a gente se reúne, sim. Com o Juiz, a gente tem um grupo no "zap" que funciona maravilhosamente bem. A gente vê todas as outras situaçôes com os outros Conselhos, e o Juiz 'tá fazendo um trabalho muito bonito. Se a gente tem dificuldade de resolver, a gente aciona ele. As vezes como "zap" mesmo é resolvido. Mas, às vezes, quando a gente não consegue resolver, a gente marca uma reunião e diz: "Olha, será que tem como a gente agendar pra conversar? Será que tem como a gente agendar com a Promotoria?". Eu sinto uma dificuldade, às vezes, porque os Promotores mudam muito, então, às vezes, a gente tem uma afinidade... é normal; aí, dai a pouco, "pá", muda.

Já esse promotor ressalta a importância dos indivíduos em face das instituições, defendendo que a rede é "muito mais CPF do que CNPJ":

\section{Promotor:}

Uma outra coisa também que, assim, que eu acho que acontece muito com essa questão da rede é que a rede é muito mais CPF do que CNPJ, ela é muito mais o fulano, não éo MP, a promotoria, éuma determinada pessoa.

O segundo aspecto associado a situações de cooperação é a percepção da importância da troca de informações entre as instituições. Em geral, o que se tem em mente neste caso é a troca de dados em torno de um caso concreto, o que sem dúvida reforça a importância das relações pessoais, ao mesmo tempo que torna mais preocupante o fato de que não se dispõe de sistemas integrados de gestão de dados administrativos. No trecho a seguir, uma profissional do Cras aponta a dificuldade da troca de informações, salientando a possibilidade de atendimento de uma mesma família por duas agências da rede e sem intercâmbio de informações entre elas. E o relato é ainda mais relevante por tratar da falta de troca de informações com o Creas, que está subordinado à mesma coordenadoria do governo municipal:

Profissional do Cras:

Não éporque a gente não tem esse sistema ideal, e assim a realidade é uma realidade muito dura, porque ao mesmo tempo que eles demandam todo esse monitoramento, a gente não tem recursos pra isso. Então, muitas vezes uma família que chegou pro Creas e ele está atendendo, eu nem sei, é do nosso território, é uma familia que poderia estar..., que, às vezes, está sendo acompanhada pela gente, mas chega lá no Creas e fica por lá. Não tem esse cruzamento de dados. É um esforço 
muito hoje da CASDH (Coordenadoria de Assistência Social e Direitos Humanos), da gente estar cruzando esses dados pelos nossos esforços, pura e simplesmente.

Se é certo dizer que a gestão em rede pressupõe um fluxo contínuo de informações, faz-se necessário pensar nas ferramentas de apoio para que essa demanda aconteça de forma favorável ao êxito da ação empreendida. Nesse sentido, como já notado, ferramentas tecnológicas de uso pessoal despontam como um instrumento visto como capaz de agilizar o acesso, a troca e a gestão das informações e conhecimentos pertinentes a cada processo. O que certamente traz outros problemas, relacionados à memória administrativa e à impessoalidade na gestão das informações.

A valorização das relações pessoais e da troca de informações se completa com a indicação de um terceiro fator considerado muito importante para a cooperação entre as agências, qual seja, a realização de reuniões, percebidas como uma ferramenta de gestão que propicia a tomada de decisões conjuntas, ao mesmo tempo que fortalece o compromisso entre os diferentes atores. Muitas vezes, as reuniões são relevantes até mesmo para esclarecer o papel de cada agência, já que não raro existe o desconhecimento das competências de cada uma. Nesta passagem, um conselheiro, ao falar de sua rotina, e com que agências costuma se reunir, salienta a importância desse caráter das reuniões:

\section{Conselheiro:}

Agora tem creche, tem o Cras, né? Tem a saúde, né? Clinica de família... A gente quer fazer uma reunião com "Agentes comunitários de Saúde", que é importante, que são eles que também vão até às residências e veem como que tá a situação das familias. Com os professores, os diretores de escola, o que é importante, a gente vai muito às escolas. Polícia, né? A gente agora quer marcar de a gente ir a cada delegacia pra gente explicar qual éo trabalho. Porque, às vezes, a pessoa não sabe mesmo, o delegado não entende como éo trabalho.

Verificamos, também, a preferência por um certo tipo de reunião, chamada pelos diferentes agentes de "roda de conversa", que passa uma ideia de horizontalidade, ou seja, teria uma característica de troca de ideias entre os atores. A importância das reuniões como parte inerente ao funcionamento das redes é de tal amplitude, que a maior ou menor facilidade e intensidade para se reunir com determinado ator tende a funcionar como um parâmetro para qualificar o grau de proximidade em face do mesmo.

A delimitação do que há de comum quanto à percepção do direito da criança e da rede sugere que estaria em curso a conformação do compartilhamento de uma cultura de rede. E a importância desse achado se vê realçada pelo fato de apenas uma 
parte minoritária dos entrevistados manifestar indiferença em relação à rede, seja por alegar desconhecimento acerca de seu funcionamento, seja por simplesmente não ter opinião a respeito, ou, ainda, por considerar seu trabalho irrelevante. E esses são, em sua grande maioria, profissionais da escola.

Mas se a pesquisa permitiu a identificação de alguns aspectos que denotam a conformação do que estamos denominando de uma gramática comum, bem mais eloquentes foram as evidências a respeito da especificidade de cada agência, o que permite explorar as dissonâncias existentes entre os atores, tanto no que se refere à sua percepção do direito, quanto no tocante à percepção da rede.

\section{A singularidade de cada agência}

Ao menos em princípio, não deve haver propriamente surpresa em face das significativas diferenças encontradas na percepção dos diferentes atores diante do direito da criança e da rede, uma vez que é próprio da noção de rede seu caráter polissêmico, que somente se materializa nas relações concretas mediante a realização de tradução por parte de cada um de seus atores ${ }^{8}$. No entanto, como se viu, a ação cooperativa pressupõe um tipo de entendimento entre os atores em torno de situações concretas, o que pode ser favorecido ou prejudicado caso se leve em conta a forma como cada agência tende a perceber o direito da criança e do adolescente, e a forma como percebe a outra agência.

\section{A escola}

As entrevistas realizadas com os profissionais da escola indicam que, ao menos para os professores, a percepção do direito da criança é, em geral, construída a partir do cotidiano da sala de aula. $\mathrm{Na}$ escola, é frequente uma leitura que tende a associar o direito com o empoderamento do aluno, muitas vezes visto segundo uma percepção negativa. Como nas passagens a seguir, extraídas de entrevistas com professores:

A sensação que me dá é que desde muito cedo eles estão gritando por autonomia. Agora, que autonomia é essa, né? É uma autonomia... protegida.

Alguns mais rebeldes você toca assim no aluno: "Não me encosta não!", né? Qualquer coisa: "Você tá me constrangendo!". Então, existe uma apropriação de um... De um... De um direito que existe, mas que eu acho, assim, eu vejo de uma forma um pouco exacerbada, um pouco deturpada e que a gente tenta falar sobre isso em sala de aula, discutir as coisas, explicar, né?

8. Aqui, tomamos de empréstimo de Bruno Latour (1994) a noção de tradução, que seria cara às redes tecnocientíficas. 
Possivelmente por não contar com espaços de reflexão sobre o direito da criança, a percepção do professor sobre a questão é muito condicionada pela experiência concreta e singular na sala de aula. Por isso, o direito da criança tende a se converter em uma espécie de parâmetro para uma negociação que ocorre no chão da sala de aula, segundo critérios contingencialmente definidos. $\mathrm{O}$ trecho de uma entrevista de um professor, destacado a seguir, registra bem essa característica:

Então é uma imagem que eles veem: "Se a gente se comporta, a gente sai dez minutos mais cedo." Tudo flui melhor, se a gente dá uma moral a ele, e ele dá uma moral pra gente. É uma retribuição, e isso eu ganho muito, dez minutos que perdi nessa aula, mas hoje a minha aula fuiu praticamente sem eu chamar atenção de ninguém; todo mundo copiou, todo mundo fezo dever, todo mundo me entregou.

Apesar de essa forma contingencial favorecer a conformação de percepções variadas, também é verdade que, como já visto aqui, a exemplo do que se verifica entre os demais agentes da rede, também subsiste entre os professores a tendência a se valorizar uma concepção sistêmica do direito da criança. De fato, os entrevistados realçam as diferentes carências que, segundo eles, comprometem a efetividade dos direitos e a sua própria capacidade de atuarem como fiadores desses direitos, que, como no caso do trecho destacado a seguir, se confunde com a impotência da própria escola.

$E$ E, então, eu acho que, por a escola não ser atrativa, o aluno não tem vontade de vir pra escola, $e$ esse aluno sai da escola, né, evasão escolar.. O mundo lá fora é muito mais atrativo.

Quando se analisa o material que trata da relação da escola com a rede, identifica-se uma dinâmica caracterizada por uma espécie de círculo vicioso. Seus profissionais não conseguem perceber os agentes da rede como aliados reais no enfrentamento das dificuldades rotineiras e muitas vezes dramáticas com que a escola tem que lidar. Em diferentes entrevistas, fica evidente que seu isolamento em face da rede decorre de uma percepção negativa sobre os agentes não escolares. No trecho a seguir, um professor aponta o desconhecimento em relação ao CT, mas, mesmo sem conhecê-lo, entende que os conselheiros "não parecem pessoas muito preparadas":

Assim... Eu não tenho... pra avaliar, acho que eles são omissos, mas também, assim, eu nunca levei isso a cabo, assim: "Ah, vou encaminhar esse caso aqui, e a diretora liga pro Conselho Tutelar e tal'... porque os conselheiros tutelares, eles não me parecem pessoas muito preparadas. 
Um ponto sensível da relação da escola com a rede é a questão da inclusão de crianças/adolescentes em situação de conflito com a lei, ou simplesmente por ser "menino de rua”, uma vez que a escola não reconhece os atores da rede, muito especialmente o CT, como potenciais aliados. No trecho a seguir, uma professora assume não saber como "lidar com esse tipo de aluno":

Eu não sei muito sobre essa parte do estatuto, do conselho, porque eu não fico ligada em nada disso, porque eu 'tô... não acredito, entendeu? Eu vejo muito... e se eu depender desse pessoal todo, até esses meninos obrigados a entrar na escola, esse garoto infrator, menino de rua, tem que estudar! Aí põem aqui, não é.... eu não sei lidar com esse tipo de aluno.

Ora, tendo em vista os enormes desafios cotidianos que a escola tem de enfrentar, e o isolamento em face da rede que caracteriza sua atuação, não surpreende que a resultante dessa situação seja um sentimento difuso de ameaça que, como caracterizado pelos dados coletados, aparece, de um lado, em uma leitura muito negativa dos atores da rede, especialmente do CT, visto como um agente que perturba a correlação de forças existente na escola. E de outro, por uma sensação de impotência em face de crianças e adolescentes supostamente empoderados pelo ECA. No trecho a seguir, a entrevistada, diretora adjunta de uma escola, ao responder a uma pergunta sobre como avalia a atuação das outras agências da rede, apresenta uma leitura muito negativa do CT, "um órgão que não faz nada", para salientar que, de um lado, tem-se um "menor que vai te esculachar", mas que é protegido, e de outro, um professor fragilizado.

No primeiro ano eu odiava o Conselho Tutelar, tá?, odiava. Primeiro ano que eu 'tava aqui na gestão, odiava, assim, atéporque eu sei como funciona, porque eu também sou advogada. Então, assim, ele é um órgão que não faz nada, ele não tem poder de polícia, ele é um órgão protetivo do menor que, na verdade, vai te esculachar ali, quando na verdade você tá precisando de poder depolicia...

Aqui, o círculo vicioso se fecha. Desse sentimento de ameaça em face de um estudante supostamente empoderado, e dessa percepção negativa em face da rede, deriva uma maior resistência a participar dela, com o que se aprofundam ainda mais o isolamento da escola e sua dificuldade de lidar com os desafios inerentes a um público que vive em uma cidade muito pouco amável com crianças e adolescentes, especialmente com aqueles moradores de territórios populares. $\mathrm{Na}$ verdade, não seria exagero afirmar que, a rigor, a escola não lida com a rede, ou, se lida, o faz de forma muito instrumental, isto é, não se valendo do que poderia ser 
uma articulação capaz de proteger crianças e adolescentes em face de situações de vulnerabilidade escolar.

Portanto, a forma como os profissionais da escola lidam com a rede - ou talvez o mais correto seria dizer: não lidam com a rede - deve muito à forma como eles percebem o direito da criança. Como se viu, é a partir da experiência concreta na sala de aula, ou seja, na interação com os estudantes, que os profissionais elaboram sua percepção, e tal dinâmica parece levar a uma concepção muito pessoal sobre o significado do direito da criança. E como não parece haver um maior investimento no sentido de se construir uma concepção compartilhada a respeito do direito da criança entre os profissionais da escola, não surpreende que eles sequer percebam a rede de proteção, ou simplesmente a percebam de forma negativa, reiterando com isso o isolamento da escola. Ora, tal estado de coisas parece grave, na medida em que se espera da escola um papel decisivo na promoção de uma cultura de direitos da criança e do adolescente. Mais do que isso, espera-se dela que atue como principal âncora da rede de proteção dos direitos da criança, o que demandaria uma predisposição para participar como gestora da rede.

Enfim, ao que tudo indica, o padrão de relação dos profissionais da escola com o direito da criança e com a rede de proteção denota que eles ainda se aferram à lógica própria das instituições - que pressupõe o desempenho de papéis sociais, segundo padrões normativos previamente estabelecidos. E deve pesar muito para essa configuração o fato de a escola não estar organizada para se abrir a outras formas sociais que não a de lidar com alunos/estudantes; enquanto a lógica do ECA pressupõe que se trabalhe com crianças e adolescentes.

Não surpreende, portanto, que os profissionais da escola percebam o ECA como uma ameaça, e como parte do conjunto de fatores que identificam como causadores da crise escolar. Por esse motivo, e aqui estamos seguindo as pegadas da proposta teórica de Dubet (1994), eles não podem se ver como parte de uma rede de proteção de direitos, o que demandaria que se pensassem como sujeitos que constroem o sentido de suas ações no plano da experiência, articulando diferentes lógicas e linguagens, o qual teria no trabalho propriamente escolar apenas uma de suas dimensões. Afinal, não custa lembrar que no mundo das redes, ao contrário do mundo das instituições, as fronteiras já não são mais tão nítidas! Disso se pode concluir que a principal resistência ao ECA encontrada entre os profissionais da escola não é tanto aquela eventualmente manifesta como posição política, mas, sobretudo, aquela presente em uma prática cotidiana que não se coaduna com o tipo de operacionalização do direito proposto pelo ECA. 


\section{O Conselho Tutelar}

No conjunto das entrevistas com os conselheiros, o quadro que se extrai é o de que o Ст está em um lugar intersticial, entre a lógica normativa do direito e as moralidades do mundo da vida. Tal condição intersticial pode ajudar a explicar parte dos ruídos acima identificados na relação do Conselho com os demais agentes da rede; e até mesmo os conflitos de competência com o MP, acima aludidos.

Com efeito, os conselheiros partilham um código intelectual caro ao campo do Direito, adotando uma concepção normativa do ECA. Na parte da análise que se circunscreve à percepção do direito da criança, fica evidente esse risco do CT se autojudicializar, o que não é sem consequências quando se considera que seu papel deve ser o de atuar como mediador entre o campo do direito e o mundo da vida, aproximando o sistema judicial de configurações que muitas vezes estão mergulhadas na moralidade das tramas familiares e nos conflitos que envolvem a vizinhança e a escola. A rigor, о Ст pode ser entendido como um ator que atua na fronteira entre a judicialização e a juridicização?.

Os conselheiros parecem conscientes de que, se penderem para o polo jurídico, perdem em capacidade de mediação, afastando-se dos atores que operam diretamente no mundo da vida. Quando se analisa mais detidamente sua percepção sobre a rede, verifica-se que os profissionais do Ст posicionam o órgão como mediador de linguagem, evitando se colocarem como atores jurídicos. De fato, a percepção da rede pelo Ст evidencia a necessidade de transformar o ECA em uma linguagem que, como vimos, não é inteiramente compreendida por outros atores, como a escola, por exemplo. Observa-se também que essa atuação em rede está sempre referida a casos concretos, na medida em que se espera dessa agência uma atenção às singularidades da situação de cada criança e adolescente, ainda que ele também possa, ao menos em tese, propor políticas públicas.

Na passagem a seguir, ao responder a uma pergunta sobre as denúncias recebidas pelo "disque denúncia", uma das conselheiras entrevistadas fala das providências que o CT toma e da sua relação com o MP e o Judiciário, deixando claro que sua atribuição não é jurídica, e que somente em último caso ingressa com "requisição", que seria um expediente para acionar a esfera jurídica.

Chega bastante [denúncias]. A gente não é criador de prova, mas a gente tem que averiguar. Como que eu vou afirmar que o pai tá abusando se eu não tenho essa capacidade? A gente

9. Ainda que trate desse tema na área da saúde coletiva, o artigo de Felipe Asensi (2010) é uma boa referência para uma melhor compreensão dessa fronteira entre a judicialização e a juridicização. 
confunde, né? Nós não somos criadores de prova, mas averiguamos. A gente faz o relatório. E manda pra Promotoria e manda pro Juizado. Ai, vê se tá precisando de alguma coisa, porque a gente não faz, aqui não faz nada da parte jurídica. Aquiéum órgão não jurisdicional, que éfeito também pra desafogar o Juizado. Por conta disso também. A gente encaminha pra Defensoria Pública, né? Conflito... tudo que é de interesse, a gente conversa, identifica, a gente requisita. A gente encaminha, a gente requisita também. Que a requisição é um pedido legal, tem que ver, solicitação não. Quando a gente não consegue, o que a gente faz é requisição.

Em suma, a análise sobre o perfil do Conselho Tutelar indica que o órgão ocupa um lugar híbrido, sempre correndo o risco de ser capturado por uma percepção sistêmica e estatutária do direito da criança, com a adoção de um código intelectual - talvez fosse forte falar em habitus, ao menos no sentido proposto por Bourdieu (2003) -, moldado segundo a lógica derivada do Judiciário e do MP. Com isso, parece fazer parte de sua posição no ordenamento jurídico e social criado pelo ECA o risco de se tornar refém de uma cultura jurídica, com evidentes elementos de uma tradição na qual o Direito é distante do plano da sociabilidade da vida cotidiana, ela própria atravessada por diferentes moralidades. Mas as evidências por nós reunidas indicam que, quando instados a falar sobre sua atuação na rede, os profissionais do CT posicionam o órgão como mediador de linguagens.

É possível que essa condição anfíbia seja mesmo a forma que torna possível aos conselheiros atuarem nas duas pontas, a do Estado e a da sociedade, a fim de defenderem os direitos das crianças. Mas também é provável que essa mesma condição contribua para tornar sua tarefa diária mais complexa e muitas vezes de difícil compreensão para os demais atores. Por ser uma agência criada pelo ECA, e por ser seu principal fiador perante a sociedade, as dificuldades cognitivas e de identidade do CT são, por isso mesmo, o melhor reflexo do quanto é desafiadora a recepção desse novo direito; e a resistência apresentada pela escola possivelmente seu mais evidente sintoma.

\section{o Cras}

Diversamente do que sobressai na análise do CT, onde a dimensão normativa oriunda do direito é mais presente, entre os profissionais do Cras, epistemologicamente dominado pelo campo do Serviço Social, a tônica das interações é um elemento muito forte na narrativa dos atores, e isso provavelmente se deve à natureza mesma do trabalho no Cras, para o qual é central o relacionamento com as famílias, às vezes de modo bem personalizado. Os profissionais que se encontram na "ponta" do atendimento indicam ter proximidade com as crianças e as famílias, não raro tendo 
que tomar atitudes diante de determinadas violações de direitos por estarem em uma posição de maior exposição. Por outro lado, costumam ressaltar essa proximidade com as famílias atendidas como um elemento positivo e até mesmo indispensável à sua atuação, já que geradora de potencial empatia com os indivíduos atendidos.

A análise da dimensão da percepção do direito da criança indica a coexistência de duas vertentes na atividade do Cras. De um lado, uma concepção sistêmica, que aparece em relatos que falam de faltas estruturais, geralmente vinculadas à família e também à escola. Aqui, a narrativa geralmente privilegia os efeitos da violência e da vulnerabilidade das comunidades em que elas moram, e o Cras aparece mergulhado em um oceano de problemas, tendo sua atuação constrangida por urgências que se repetem.

De outro lado, nota-se uma concepção do direito da criança que lhe atribui um caráter negativo, na medida em que de algum modo contribuiria para fragilizar os laços familiares, seja por servir a processos de transferência de responsabilidades para os filhos, seja por tornar menos claras as fronteiras entre direitos e deveres. No trecho a seguir, extraído de entrevista com uma profissional do Cras, isso fica evidente, e quando pensamos que os profissionais do Cras são intérpretes privilegiados dos laços familiares do mundo popular, sua preocupação em face do impacto do ECA não deixa de soar como grave advertência.

Acho que essa coisa do limite de dar... perdeu essa questão de limite, acho que o direito da criança realmente tem que ser preservado, elas têm direito sim, mas deveres também. Tirar um pouco o enfoque do direito iria ser mais legal nesse momento.

Para uma compreensão mais plena da complexa relação do Cras com o ECA, é muito importante considerar que, se é verdade que seus profissionais tendem a ler com certo pessimismo o efeito do direito da criança sobre a organização da família popular, também é verdade que faz parte do diagnóstico que dá sentido ao seu trabalho a premissa de que seu esforço para evitar que se percam os laços afetivos familiares (situação que demandaria um outro tipo de abordagem, a cargo do Creas) somente se justifica caso se considere que estamos diante de sujeitos de direitos, que mais do que simplesmente protegidos precisam ser respeitados. E é por isso que, ao menos no que se refere à sua relação com o ECA, o trabalho do Cras é fundamentalmente o de construtor de redes nos territórios populares.

Talvez por isso, diferentemente do que se observa na escola e no CT, no Cras prevalece uma leitura positiva da relação de parceria com as demais agências, tendo sido citadas, além do Creas, CT e MP, a unidade básica de saúde, em especial pelo trabalho que os agentes comunitários de saúde fazem, enquanto fonte de informação para que o Cras localize um determinado endereço na Rocinha. No trecho da entre- 
vista, abaixo destacado, ao responder a uma pergunta sobre a relação com as demais agências, uma assistente social do Cras relata que são feitas ações em conjunto com a Saúde, muito por conta do Bolsa Família, que é uma política pública que articula as duas áreas. A assistente social também conta que há uma proximidade com o Conselho Tutelar, "porque não tem como não trabalhar juntos"; já em relação à escola, informa que são realizadas reuniões para o desenvolvimento de um projeto, que fica sob a responsabilidade de outra assistente social:

\begin{abstract}
Sim, nós trabalhamos, sim; por exemplo, às vezes, vem um, semana passada ou semana retrasada, recebemos o processo de denúncia de um idoso; então, como a Rocinha é muito complicada de endereço, eu fui até a clinica da familia, que era da área, pro agente de saúde me levar até lá. Nós trabalhamos muito assim, como Conselho Tutelar também, porque não tem como não trabalhar juntos, a escola, a questão das reuniões nas escolas, que é... esqueci o nome do projeto, quem faz mais isso é a outra assistente social. Que tem um projeto na escola, eu esqueci o nome, mas tem umas reuniōes, às vezes mensais, às vezes quinzenais. A saúde, por exemplo, ela faz reuniäo junto com a gente, porque tem uma funcionalidade do Bolsa Familia, que épara pesagem e vacinação, então entramos nessa reunião também, então fazemos em conjunto, entendeu?
\end{abstract}

Com base no perfil apresentado por seus profissionais, o Cras se destaca como um articulador de diferentes atores em um determinado território, incluindo aqueles que realizam ações sociais ${ }^{10}$. Mas essa busca por parceiros costuma assumir um caráter de permanente recomeço, já que boa parte dos potenciais aliados que atuam no território opera por meio de projetos com começo, meio e fim. Seja como for, em seus relatos, os profissionais do Cras deixam claro que, na base do ensaio e erro, a agência procura valorizar o que há de organizado nos territórios e, nesse sentido, mesmo sem garantia de êxito em face de casos concretos envolvendo famílias em situação de vulnerabilidade, ainda assim acreditam que seu trabalho possa contribuir para o incremento do que podemos caracterizar como capital social local - no sentido atribuído ao termo por Robert Putnam (1996). Por isso, para os profissionais do Cras, quando se fala em rede, deve-se ter em mente o duplo significado que ela assume para essa agência: a de uma articulação entre atores diretamente envolvidos no ECA; e a de uma articulação entre atores de diferentes tipos que atuam em um determinado território popular. Na sua prática, contudo, essa fronteira conceitual não parece ter maior importância. Como afirma uma das profissionais da Cras: "Parceiros sempre, sempre. Não dá conta. A máquina estatal está sempre muito a desejar”.

10. Para uma discussão sobre a importância do território para a Assistência Social, ver Nascimento e Melazzo (2013); e Koga e Alves (2010). 


\section{O Ministério Público}

Na parte da pesquisa que tratava especificamente da percepção do direito da criança, ficou evidente que entre os promotores estudados prevalece uma concepção sistêmica, que é muito expressiva do lugar que o Ministério Público ocupa na rede de proteção, uma vez que sua condição de agente estatal, guardião da ordem jurídica, faz com que sua relação com o direito da criança seja fundamentalmente normativa e vertical. Por essa razão, não surpreende que o promotor tenda a ver o direito da criança com o olhar de quem está no vértice de um subsistema, pensando-o a partir do ângulo do texto legal. Esse modo de perceber o direito da criança define a forma pela qual percebe e atua na rede, e o modo pelo qual pratica o direito da criança.

Destacado a seguir, o trecho da entrevista com uma promotora chama a atenção para esse aspecto:

Eu percebo uma dificuldade de todos os atores e aí incluiria o Ministério Público, de perceber essa criança como sujeito de direitos, para percebê-la, às vezes, como objeto da disputa, e ai assim nesse aspecto eu acho que o Ministério Público tem uma função bem particular, porque ele éo substituto processual da criança e do adolescente previsto no ECA. Essa... essa função está lá, tá no artigo 201, quem é o substituto processual. Então, assim é muito importante que o Ministério Público perceba essa criança como sujeito de direitos, porque é ele que éo advogado, entre aspas, previsto pra representar perante o juizo; então, assim, eu entro com ações de responsabilidade civil em favor da criança...

A análise do material sobre a percepção da rede permite identificar que o MP vem desempenhando, basicamente, quatro papéis diferentes, a saber: o de fiscal da rede; o de fiador da rede; o de operador da rede; e o de uma agência que se vê chamada a assumir papéis substitutivos aos de outros atores da rede. Enquanto fiscal da rede, o MP se propõe a exercer o papel de supervisor, que monitora os diferentes atores; na condição de fiador, como órgão que zela pelo cumprimento das responsabilidades de cada agência; na de operador da rede, vê-se chamado a atuar como seu fomentador, promovendo a aproximação e o diálogo entre os atores; por fim, também apareceu no material gerado pelas entrevistas com os promotores uma percepção de que, ao menos pontualmente, o MP pode ter que desempenhar papéis substitutivos aos de outros atores, que, por essa ou aquela razão, não conseguem fazer frente a suas tarefas.

Assim, se é verdade que os promotores que lidam diretamente com o ECA se percebem no vértice de um subsistema, posição compatível com a de um órgão que deve atuar enquanto guardião e supervisor do bom funcionamento da rede, também é verdade que eles percebem que o MP precisa estar suficientemente próximo para 
atuar como parte da rede. Ora, a percepção normativa e sistêmica que os promotores fazem do direito da criança, e as exigências que recaem sobre o MP na sua atuação em rede apontam para um quadro de desencontros entre seu papel de guardião e seu papel de parte da rede, que ele, em tese, deve supervisionar. O fato de o MP ter uma estrutura basicamente restrita aos promotores, que por isso mesmo tendem a ficar mais confortáveis quando se percebem no vértice do subsistema, indica que, ao menos no âmbito do direito da criança e do adolescente, a atuação do MP deixa vazios institucionais, que a lógica de especialização funcional com que vem organizando a divisão de trabalho de suas promotorias não é capaz de evitar. O trecho a seguir, de uma entrevista com uma das promotoras, é, sob esse aspecto, bastante interessante:

De fato, a gente percebe dificuldade, eu percebi assim, que a minha visão é macro, a individual é da promotoria [de outra promotora], que eles não andam se falando, que há dificuldade de saber até aonde vai a atribuição do Conselho Tutelar, até aonde vai a do Creas. Então os conselheiros tutelares, em regra, entendem que não éo papel deles ir para a rua, pra abordar essa criança que está em situação de rua. O Creas na verdade sabe que o papel é dele, mas, às vezes, precisa da parceria do Conselho nos casos mais dificeis; então essa reunião, eu achei que foi muito produtiva.

\section{Conclusões}

Na exposição dos dados empíricos, procuramos, em primeiro lugar, destacar os aspectos comuns identificados na percepção do direito da criança e da rede de proteção entre os profissionais das diferentes agências pesquisadas. Com isso, salientamos a tendência, recorrente entre os diferentes tipos de entrevistados, de se assumir uma concepção sistêmica quando se pensa no direito da criança, o que faz com que eles se vejam igualmente impotentes diante do que percebem como deficiência da estrutura de serviços e instituições existentes, bem como da violência, pobreza e desigualdade social. Para além dessa marca, dominante entre os profissionais da rede de proteção, também identificamos um conjunto de aspectos que denotam o compartilhamento de uma gramática comum. Quanto a isso, um dado importante é a identificação de que tanto o direito da criança quanto a noção de rede de proteção fazem parte da imaginação institucional dos profissionais, informando seu horizonte e suas expectativas, bem como as críticas que formulam ao seu funcionamento. Para sintetizar, poderíamos afirmar que é como se eles opusessem uma concepção sistêmica, granítica, dos problemas que se precisa atacar, ao modelo flexível e horizontal da rede. Nessa chave, parece proeminente entre os profissionais entrevistados a tendência a se ler a gestão em rede como uma atividade que opera em escala artesanal com problemas cuja natureza seria sistêmica. De todo modo, os próprios profissionais entrevistados 
ensinam como a rede pode se tornar mais potente, apontando três modos de ação favoráveis à criação de situações de cooperação: a valorização das relações pessoais, a necessidade de se incrementar a troca de informações entre as agências, e a importância dos encontros presenciais por meio de reuniões.

Acreditamos que esse mapa dos fatores comuns apontados pelos profissionais das diferentes agências pode ser tomado como um bom guia para o fortalecimento do funcionamento das redes.

Em um segundo movimento, procuramos apontar os aspectos mais salientes da forma como cada agência pensa o direito da criança e atua na rede. O primeiro achado, e talvez o mais importante, diz respeito à escola. $\mathrm{O}$ fato de não haver entre seus profissionais um entendimento compartilhado do direito da criança, e de ele ser visto muitas vezes como potencial ameaça aos critérios de justiça escolar, o que inclui a autoridade do professor; e o fato de a escola não favorecer uma articulação capaz de gerar cooperação com vistas a proteger crianças e adolescentes em situações de vulnerabilidade escolar denotam uma configuração de distanciamento da escola em face da filosofia proposta pelo ECA, que, a rigor, não tem como ser efetivado fora da rede, e não tem como se realizar se não se considera a integridade do direito de cada criança ${ }^{11}$. Temos aqui, sem dúvida, um importante obstáculo à decantação do direito constitucional inscrito no ECA.

Um segundo achado refere-se ao risco de captura do СT pelo campo do direito. E isso, como procuramos indicar, não é sem consequências para a definição do caráter e do alcance de sua atuação. Um terceiro achado diz respeito à forma pela qual o MP se vê desafiado pelo ECA, que exige que ele seja ao mesmo tempo fiscal e parte da rede, papéis que não deixam de ser conflitantes. Finalmente, também verificamos que o Cras enfrenta, no plano da vida cotidiana, problemas estruturais. Também vimos que sua atuação está fortemente condicionada pelas características ecológicas de cada território.

Portanto, voltando à questão de partida, acerca do processo de decantação do ECA, talvez pudéssemos afirmar que a pesquisa revela uma transição inconclusa entre o modelo burocrático, caro às formas anteriores de direito, e o modelo em rede. Mas também revela que não há motivos para imaginarmos que a transição fatalmente se completará na direção do modelo em rede. Ao contrário, existem muitos motivos para se acreditar que a relação entre essas agências poderá ficar estagnada entre um modelo e outro. Para superá-lo, e com isso tornar possível realizar mais plenamente o espírito do ECA, um bom começo pode ser o de se ter clareza que o ECA não apenas trouxe um novo paradigma de direito da criança, mas também um novo modelo de

11. Sobre a noção de “vulnerabilidade escolar”, ver Burgos et al. (2014). 
gestão, o que também implica reconhecer que muito da resistência a ele é menos uma objeção de fundo aos seus aspectos materiais, e mais uma rejeição, parcial ou completa, à sua forma processual.

Mas também é forçoso reconhecer que a estrutura criada para proteger as crianças foi engolfada por processos estruturais que se desenrolam a partir dos anos de 1990, que ajudam a explicar o sentimento de impotência dos profissionais identificado pela pesquisa. De modo especial, seria importante considerar a crescente presença do mercado no mundo popular, e seus efeitos sobre a sociabilidade nos territórios populares; de um mercado, vale dizer, que funciona à base da exploração do trabalho precarizado, e de ampla privação de direitos, urbanos e de consumidor. Com a chegada forte de um mercado de regulação, também cresce na vida popular a violência associada ao tráfico de drogas e de armas (Telles, 2010; Feltran, 2014).

É tendo em mente essas circunstâncias, que precisamos enfrentar com seriedade a questão fundamental: abandonar o modelo em rede ou insistir nele, trabalhando com energia para que ele possa de fato funcionar para proteger as crianças e adolescentes mais vulneráveis? Afinal, não é demais lembrar que o Brasil é o país com maior número de casos de homicídios de adolescentes em todo o mundo ${ }^{12}$.

\section{Referências Bibliográficas}

AsEnSI, Felipe Dutra. (2010), "Judicialização ou juridicização? As instituições jurídicas e suas estratégias na saúde”. Physis: Revista de Saúde Coletiva, 20 (1).

Boltanski, Luc \& Chiapello, Éve. (2009), O novo espírito do capitalismo. São Paulo, Martins Fontes.

Bonnan, Jean-Claude. (2001), "Justice de proximité ou justces de solidarité". Revue Droit et Cultures, 2001/3: 125-131.

Bourdieu, Pierre. (2003), O poder simbólico. Rio de Janeiro, Bertrand do Brasil.

Burgos, Marcelo (coord.). (2014), A escola e o mundo do aluno. Estudos sobre a construção social do aluno e o papel institucional da escola. Rio de Janeiro, Garamond.

Burgos, Marcelo; Camasmie, Mariana J.; Castro, Rafaelle; Carneiro, Aristóteles V.; Matos, Marcelo \& Monteiro, Sarah L. (2014), "Infrequência e evasão escolar: nova fronteira para a garantia dos Direitos da Criança e do Adolescente”. Revista Desigualdade e Diversidade, Departamento de Ciências Sociais, Puc-Rio.

Casagrande, Cássio. (2008), Ministério Público e a judicialização da política. Estudo de casos. Porto Alegre, Sérgio Antonio Fabris Editor.

12. De acordo com o Unicef (2019), entre 2007 e 2017, 107.270 adolescentes entre dez e dezenove anos foram assassinados. 
Castro, Rafaelle Monteiro (2018), Crianças e adolescentes enquanto sujeitos de direitos no Brasil Pós-ECA: o Conselho Tutelar e a Rede de proteção. Rio de Janeiro, tese de doutorado, PPGCIS/PUC-Rio.

Dubet, François. (1994), Sociologia da experiência. Lisboa, Instituto Piaget.

Feltran, Gabriel. (2014), "O valor dos pobres: a aposta no dinheiro como mediação para o conflito social contemporâneo". Caderno CRH, 27 (72): 495-512.

FLeURY, Sônia. (2005), "Redes de políticas: novos desafios para a gestão pública”. Administração em Diálogo, 7.

LATOUR, Bruno. (1994), Jamais fomos modernos. Rio de Janeiro, Editora 34.

Lessa, Renato. (2008), “A Constituição como experimento de filosofia política”. In: Oliven, Ruben; Ridenti, Marcelo \& Brandão, Gildo Marçal. A Constituição de 1988 na vida brasileira. São Paulo, Anpocs/Hucitec.

Mota, Luis F. \& Bittencourt, Bernadete (2019), “Governação pública em rede: Contributos para sua compreensão e análise (em Portugal e no Brasil)". Tempo Social, Revista de Sociologia da USP, 31 (2): 199-219. Disponível em http://www.scielo.br/scielo.php?script=sci arttext\&pid=S0103-20702019000200199\&lng=en\&nrm=iso.

Oliveira, Rafaela. (2015), Judicialização da educação infantil. Juiz de Fora, tese de doutorado, Faculdade de Educação da Universidade Federal de Juiz de Fora, UfJF.

Pereira, Potyara Amazoneida Pereira. (2007), "A assistência social prevista na Constituição de 1988 e operacionalizada pelo pNas e pelo Suas". Ser Social, 20: 63-84. Disponível em https://periodicos.unb.br/index.php/SER_Social/article/view/12767.

Putnam, Robert. (1996), Comunidade e democracia. Rio de Janeiro, Editora da FGV.

Rosemberg, Fúlvia. (2008), “Crianças e adolescentes na sociedade brasileira e a Constituição de 1988”. In: Oliven, Ruben; Ridenti, Marcelo \& Brandẽo, Gildo Marçal. A Constituição de 1988 na vida brasileira. São Paulo, Anpocs/Hucitec.

Telles, Vera da Silva. (2010), "Nas dobras do legal e do ilegal: ilegalismos e jogos de poder nas tramas da cidade". Dilemas. Revista de Estudos de Conflito e Controle Social, 2 (5-6): 97-127.

Unicef. (2015), ECA - 25 Anos de Estatuto da Criança e do Adolescente. Avanços e desafios para a infância e a adolescência no Brasil. Disponível em http://www.unicef.org/brazil/pt/ ECA25anosUnicef.pdf, consultado em 12/12/2015.

Unicef. (2019), “A educação que protege contra a violência”. Brochura.

Werneck Vianna, Luiz \& Burgos, Marcelo Baumann. (2005), "Entre princípios e regras: cinco estudos de caso de ação civil pública”. Dados, Revista de Ciências Sociais, 48 (4): 777 843. Disponível em http://www.scielo.br/pdf/dados/v48n4/28479.pdf. 


\section{Resumo}

Redes de proteção e a decantação dos direitos das crianças

O Estatuto da Criança e do Adolescente, aprovado em 1990, instala no país um modelo radicalmente novo de educação das novas gerações. Entre essas novidades, está a ideia de que o direito da criança deve ser difundido e administrado por um conjunto de atores que atuariam em rede. Baseado em uma pesquisa empírica sobre alguns desses atores, este artigo pretende discutir a forma como o direito da criança vem sendo compartilhado, e como a noção polissêmica de rede informa suas práticas. De modo mais específico, procura-se dar conta da forma como escolas, conselhos tutelares, promotorias especializadas na infância e adolescência, e centros de referência em assistência social lidam com o direito da criança e com sua operacionalização em rede.

Palavras-chave: Direito da criança; Gestão em rede; Escola; Conselho tutelar; Promotorias de infância; Centro de referência em assistência social.

\section{Abstract}

Protection network and settling in child rights

The Statute of the Child and Adolescent, approved in 1990, installs in the country a radically new model of education for children. Among these novelties, is the idea that the right of the child should be disseminated and administered by a set of actors who work in the network. Based on an empirical research on some of these actors, this article describes how child rights have been shared, and how a polysemic notion of the network informs their practices. More specifically, it seeks to how schools, guardianship councils, prosecution in childhood and adolescence, and public centers in social assistance deal with the right to a child and how deal with its operationalization in a network.

Keywords: Child right; Network management; School; Tutelary council; Childhood prosecution services; Public center for social assistance.

Texto recebido em 26/10/2019 e aprovado em 16/4/2020.

DOI: $10.11606 / 0103-2070 . t s .2020 .163553$.

Marcelo Baumann Burgos é professor e pesquisador do Departamento de Ciências Sociais da Pontifícia Universidade Católica do Rio de Janeiro, PUC-Rio. E-mail: burgos@puc-rio.br. 